\title{
MANAUS, UMA METRÓPOLE NA FLORESTA? A PAISAGEM ENQUANTO CATEGORIA DE ANÁLISE DA DISPERSÃO URBANA
}

\author{
Autor: Taís Furtado Pontes \\ Universidade de Brasília, UnB \\ EMail: taisfurtado@gmail.com \\ Diretor: Rômulo Ribeiro \\ Email: rjcribeiro@gmail.com
}

\section{RESUMO}

Neste trabalho são apresentados os resultados preliminares da pesquisa sobre a análise da dispersão urbana induzida por infraestruturas viárias no caso da Região Metropolitana de Manaus, capital do Amazonas, Brasil. A paisagem é proposta enquanto categoria analítica capaz de nortear novas oportunidades de intervenção urbana considerando a complexidade dos territórios periféricos difusos engendrados por infraestruturas viárias. A pesquisa busca assim, identificar critérios para leitura da paisagem metropolitana de Manaus de modo a fornecer subsídios para a interpretação do território em contribuição à instrumentalização do desenho urbano e planejamento local, entendendo o território enquanto um produto social; um projeto a serviço de uma estratégia de poder (Lefebvre, 1972); e enquanto forma, que pode ser analisada por meio de metodologias emprestadas da Morfologia Urbana e dos estudos geográficos sobre a paisagem. A investigação culminou em novos questionamentos quanto à lógica adotada pelo Estado na provisão de infraestruturas.

Palavras-chave: infraestrutura, paisagem, dispersão urbana, região metropolitana de Manaus

\begin{abstract}
This paper presents the preliminary results of the research on the urban dispersion analysis induced by the implantation of road infrastructure in the Metropolitan Region of Manaus, capital of Amazonas, Brazil. The landscape is proposed as an analytical category capable of guiding new opportunities for urban intervention considering the complexity of the diffuse peripheral territories engendered by road infrastructures. The research aims to identify criteria for reading the metropolitan landscape of Manaus in order to provide subsidies for the interpretation of the territory in contribution to the instrumentalization of urban design and local planning, understanding the territory as a social product; a project at the service of a power strategy (Lefebvre, 1972); and as a form, which can be analyzed through borrowed methodologies of Urban Morphology and geographical studies on the landscape. The investigation culminated in new questions about the logic adopted by the State in the provision of infrastructures.
\end{abstract}

Key words: infrastructures, urban morphology, landscape, Metropolitan Region of Manaus. 


\section{INTRODUÇÃO}

O Brasil é hoje o país que concentra maior parcela de sua população nas cidades, cerca de $84 \%$ (IBGE, 2010). O fenômeno, resultado da queda da taxa de natalidade e de processos migratórios internos, fez emergir grandes cidades e metrópoles num processo marcado por profundos desequilíbrios regionais. A extensa proporção territorial e a concentração histórica das principais cidades na costa marítima e no Sul/Sudeste do país contribuíram para acentuação da estrutura espacial polarizada e desigual.

A Amazônia, localizada na porção mais setentrional do país, participa amplamente da massa continental sul-americana - o Heartland, se relacionando com países fronteiriços Andinos e Caribenhos (Becker, 1974). Sua posição equatorial e sua imensa massa florestal dificultaram historicamente as ligações terrestres, principalmente no Estado do Amazonas, onde os rios predominam a estruturação da rede urbana como importantes eixos de penetração e circulação, mas que também contribuem para a dispersão da urbanização (Trindade Junior, 2010).

Manaus, capital do Estado do Amazonas, é um enclave urbanizado incrustado na floresta Amazônica e cristaliza dinâmicas sociais e econômicas de centro regional em processo de metropolização. Historicamente Manaus teve sua configuração espacial determinada por planos urbanos e projetos de grande porte. Sua metropolização, iniciada na década de 2000, acarretou fenômenos urbanos como dispersão, mobilidade e segregação social. Seguindo uma tendência particular das cidades latinoamericanas no contexto de uma economia neoliberal globalizada, a estrutura urbana tem sido produto da atuação do Estado, do mercado e da sociedade civil. O Estado intervém principalmente fornecendo infraestruturas e coordenando ações do mercado por meio de planos e projetos urbanos, enquanto o mercado imobiliário é dominante no processo de coordenação social do uso do solo e na produção da estruturação intra-urbana. Por outro lado, a sociedade civil inclui, além de agentes inseridos na cidade formal, os que dela são excluídos. Estes, sob a lógica da necessidade, mobilizam ações individuais e coletivas num continuo ciclo de ocupação/ autoconstrução/ auto-urbanização (Abramo, 2009).

Em 2007 é instituída a Região Metropolitana de Manaus (RMM) e Em 2011 foi inaugurada a ponte sobre o rio Negro, conectando Manaus aos municípios de Iranduba, Manacapuru e Novo Airão. Hoje, o território do município de Iranduba, pelo fácil acesso ao centro de Manaus, sofre forte pressão imobiliária e vem assistindo à transformação rápida da paisagem. A busca por solo acessível e barato nas franjas periféricas, reforça a produção de uma paisagem urbana difusa e introduz novos desafios para o planejamento e gestão do território. A intervenção urbana nesse contexto de dispersão é um desafio, uma vez que envolve processos rápidos de transformação em contextos de incerteza social e fragilidade ambiental.

A paisagem conformada ao longo desses canais de circulação é modelada entre e previsibilidade e a imprevisibilidade de um projeto urbano ou plano de cidade (Loures e Coelho, 2008). A capacidade que essas infraestruturas têm de induzir processos de ocupação do território nos convida a refletir sobre seu papel instrumental a serviço de um projeto de território ou de uma estratégia de poder (Lefebvre, 1972) e levanta outras questões como: Qual é o projeto de território implícito numa obra de infraestrutura viária? O que ela busca neutralizar e o que procura induzir? Quais processos de ocupação urbana ela pode produzir? E por fim, como intervir nesses territórios de incerteza em processo de rápida mutação? Nesse sentido a investigação busca desvelar as dinâmicas da dispersão urbana, por meio da análise da paisagem, explorando em que medida ela se transforma após a implantação de infraestruturas urbanas estruturantes como pontes e rodovias.

O artigo faz parte de uma pesquisa maior de doutorado e parte da hipótese de que a intervenção do Estado na provisão de infraestrutura viária fortalece o processo de dispersão urbana e de precarização social e ambiental na área metropolitana de Manaus. De modo a interpretar tal conjectura, propomos a paisagem como categoria analítica, por ser capaz não só de fornecer um modelo formal para o urbanismo, mas um modelo de concepção de processos para o planejamento do território (Allen, 1999). Assim, a pesquisa busca identificar critérios para leitura da paisagem metropolitana de Manaus de modo a fornecer subsídios para a interpretação do território em contribuição à instrumentalização do desenho urbano e planejamento local. Para atingir tal objetivo foi realizado o seguinte procedimento: i) revisão dos conceitos de território e infraestrutura; ii) reflexão sobre a configuração espacial das cidades latino americanas e o duplo processo de compactação e dispersão; iii) identificação de critérios de interpretação morfológica da paisagem por meio da revisão dos principais correntes da Geografia e da Morfologia Urbana; iv) delimitação dos critérios para a análise da paisagem da dispersão urbana; v) análise crítica do processo de urbanização difusa no município de Iranduba catalisada pela implantação da ponte de transposição do rio Negro.

\section{TERRITÓRIO: PRODUTO, PROJETO E FORMA}

A velocidade das transformações expressas nas práticas cotidianas da sociedade contemporânea induz a leituras distorcidas dos processos de ocupação do território. Essa sociedade, imersa num contexto de 
incertezas, desregulação, liberalização do mercado e flexibilização, assiste à dissolução dos vínculos entre as escolhas individuais e os projetos e ações políticas (Bauman, 2003). O território, funciona nesse contexto, como instrumento ou projeto que oculta essas tensões e (in)tenções de seus agentes. Enquanto instrumento, serve ao poder (Estado e mercado) que utiliza como máscara a racionalidade técnica dos projetos de infraestrutura viária com a finalidade de neutralizar a natureza e garantir a maior rentabilidade do solo urbano, sob o falso discurso desenvolvimentista e de garantia de acesso a meios de mobilidade.

O território é o resultado de processos que estão em constante transformação e mutação. Ele se transforma naturalmente, por exemplo, obedecendo a sazonalidades climáticas como cheias e vazantes, ou pela ação humana, por meio da introdução de objetos técnicos como infraestruturas viárias, diques, agricultura. A partir do momento em que uma população o ocupa, estabelece com ele uma relação de ordenação/ planificação e os efeitos desta coexistência podem ser observados. Por isso o território, enquanto objeto de uma construção, é uma classe de artefato, ou um produto, como coloca Corboz (1983).

O espaço enquanto produto de uma atividade sobre a natureza implica o econômico e a técnica. No entanto, vão além, são produtos políticos e espaços estratégicos. Nesse sentido Lefebvre (1972) acredita que a falsa noção de unidade explícita em um projeto de território evidencia a fragmentação do espaço social ao atribuir correspondências entre necessidades, funções, lugares e objetos sociais em um espaço "supostamente neutro". Uma vez projeto, o território passa a ser semantizado e objeto de um discurso (Corboz, 1983), que em sua legibilidade, omite a fragmentação do espaço social e ambiental. A representação desse espaço, para Lefebvre (1972), está sempre a serviço de uma estratégia. Tal espaço instrumental permite impor à força certa coesão, ou ocultar sobre uma aparente coerência racional e objetiva, as contradições da realidade. O arquiteto e urbanista trabalha sobre o mundo do visível-sensível e também opera sobre o território - conjuntos ambientais e seus materiais, conferindo-lhes sentido. Nesse aspecto Gregotti (2004) esclarece que a paisagem se antecipa à posteriores especializações metodológicas formais em diversas escalas e sugere o termo ambiente total, para orientar o conjunto de operações em diversas escalas e "dar sentido à mudança de sentido" que o trabalho de arquiteto exige e que deve ser uma busca não por uma norma, mas por um método. Assim, podemos atuar elaborando tecnologias formais de duas maneiras: organizando-as de tal modo que possibilite a produção de figuras ou "organizando em figuras as formas existentes através da instauração de um novo sentido". A implantação de uma nova infraestrutura se enquadraria no primeiro caso e a análise da paisagem resultante, no segundo, uma vez que, segundo Elinbaum (2012) referenciando Solà-Morales, "ao se aproximar racionalmente do território e representá-lo em mapas, diagramas em múltiplas escalas, se está criando um novo território".

A tradução do território em figuras permite afirmar que ele possui uma forma ou conteúdo perceptivo (Corboz, 1983). O território enquanto forma resulta de uma condensação de processos históricos e possui significados e valores. Os valores atribuídos aos lugares em cada período são fatores culturais e a forma que os aglomerados humanos adquirem, refletem esses valores próprios de um determinado tempo (Lynch, 1981). A este espaço cujas propriedades articulam forma e conteúdo, corresponde um tempo. Castells (2000) acredita que o tempo e o espaço são as principais dimensões materiais da vida humana, ao contrário da maioria das teorias sociais clássicas, que supõem o domínio do espaço pelo tempo, ele propõe a hipótese de que o espaço organiza o tempo na sociedade em rede.

\section{INFRAESTRUTURAS}

As infraestruturas são, em sua definição mais básica, redes e nós que transportam e/ou armazenam matéria, energia e informação (Contenti e Recoba, 2013). Essas redes podem ser visíveis, como estradas, terminais de transporte e carga e usinas de energia, ou invisíveis, levando dejetos pelo subsolo ou informações via satélite. São dispositivos pragmáticos que organizam e condicionam as práticas sociais no território ao mesmo tempo em que consolidam uma certa imagem de progresso vinculada a ideia de produção e eficiência. Elas possibilitam os fluxos de pessoas, objetos e informações e representam um elemento de organização social, expressando processos que dominam a vida econômica, política e simbólica de um território. ${ }^{1}$

As infraestruturas estabelecem relações complexas com o território, a paisagem e com o domínio público. São estratégicas para o desempenho social e ambiental de uma cidade ou região e operam no território trazendo implícito um projeto de paisagem. A localização de uma infraestrutura define novas localizações residências e novos eixos de expansão urbana. Ela altera dinâmicas de uso do solo e pode incidir na zona rural alterando sua estrutura morfológica.

A aparente coerência de um projeto infraestrutural oculta estratégias de mercado e de expansão territorial. Um sistema infraestrutural permite impor, por meio da racionalidade técnica, aparente coesão quanto às suas finalidades: eficiência, rapidez, oferta de terra urbanizada, promessas de vida no campo, entre outros.

\footnotetext{
${ }^{1}$ Castells, 2000
} 
Quando de fato, opera a serviço de uma estratégia, como diria Lefebvre (1972), contribuindo para a conformação do espaço instrumental, racional-funcional e funcional- instrumental. Não se trata de negar o aspecto da técnica, porém ela não deve ser entendida e aceita como algo neutro, pois na condição de meio ela pressupõe uma finalidade a ser alcançada (Ver Heidegger, Questão da Técnica).

Allen (1999), em tom de manifesto, propõe que se busquem novos procedimentos, utilizando a "caixa de ferramentas" já existente, para ampliar a aliança entre a arquitetura com a organização do território e a funcionalidade, o que ele denomina urbanismo infraestrutural, que permite um novo modelo de práxis para a estruturação do futuro das cidades, na medida em que alia a instrumentalidade da arquitetura à complexidade do real e se compromete com o tempo e com o processo de transformação do território.

\section{CONFIGURAÇÃO COM-FUSA DAS CIDADES LATINOAMERICANAS}

Apesar das diferenças regionais, há elementos que dominam as paisagens das cidades latino-americanas como a complexidade, mudança rápida, segmentação social e precarização. A disputa pelas localizações urbanas expressa o conflito entre os agentes sociais no espaço construído ou herdado. Kevin Lynch (1981) enfatiza que as localizações dos elementos físicos estão sempre relacionadas ao nível de acesso que proporcionam, enquanto outros autores destacam que além da questão do acesso há uma busca por amenidades da paisagem (Villaça, 2001) bem como por externalidades de vizinhança (Abramo, 2009), que seria a busca por residir próximo de pessoas com as quais se identifica, "entre os seus", ou da mesma classe social.

Num contexto de desregulação e liberalismo econômico onde a escassez de terra urbanizada é extrema, como nas cidades da América Latina, a configuração espacial evidencia conflitos entre atores sociais na busca por localizações urbanas. Esses territórios coordenados pelo mercado imobiliário formal e informal do solo fomentam cada um a seu modo, os movimentos de compactação e difusão (Abramo, 2009).

O mercado formal do solo, o principal estruturador do uso residencial das cidades, é um mercado segmentado, assim, promove internamente a diferenciação dos produtos por classe de renda ou grupos de consumo. Atua na dispersão ao oferecer inovações, ou produtos inéditos, de modo a motivar a demanda. Esses novos produtos estão geralmente associados aos ideais de segurança, privacidade, vida na natureza ou programa inovador, como por exemplo, áreas de lazer, esportes, áreas gourmet, entre outros. Por outro lado, o fato de o produto imobiliário ser de difícil depreciação, faz com que o próprio mercado imobiliário promova a depreciação fictícia do estoque oferecendo cada vez mais inovações. Assim ele promove a transferência das camadas de rendas mais altas para esses novos produtos, depreciando antecipadamente os imóveis desocupados por elas. Esses tornam-se novamente produto de compra para o segmento de renda imediatamente inferior. Esse mecanismo atua na extensificação da cidade "formal" ao promover as inovações espaciais para os estratos superiores da pirâmide da distribuição de renda; e na compactação urbana ao promover a substituição do estoque depreciado de forma fictícia por segmentos de estrato de renda imediatamente inferior que possuem proporcionalmente famílias mais numerosas. Além disso, a oferta de imóveis com tamanho médio inferior ao estoque existente em áreas centrais ocasiona a densificação predial, com verticalização e compactação do tecido urbano (Abramo, 2007, 2009).

Frente ao modelo elitista normativo das cidades latino-americanas, que cria barreiras institucionais para a provisão de moradias para setores populares, o mercado informal ${ }^{2}$ do solo atua pela lógica da necessidade, por meio da ocupação irregular e/ou clandestina tanto em loteamentos populares de glebas urbanas e periurbanas, quanto na compactação de áreas irregulares centrais, no Brasil essas áreas são conhecidas como favelas ou invasões. Esse mercado informal atua fora do marco institucional do direito urbanístico, do direito econômico e comercial, do direito de propriedade e dos outros direitos civis que regulariam o uso e a propriedade do solo urbano (Abramo, 2009, p. 29). O que garante o funcionamento desse mercado são as relações de confiança entre os agentes, que o autor chama de "argamassa interpessoal". Ele funciona segundo dois mecanismos que promovem simultaneamente a dispersão e a compactação do tecido urbano. $\mathrm{O}$ primeiro pelo sub-mercado de loteamentos clandestinos e irregulares, que fraciona glebas na periferia das cidades, preferencialmente em vetores de expansão, promovendo a periferização precária, comum nas cidades latino-americanas. O outro é o sub-mercado dos assentamentos populares informais (APIs) consolidados, normalmente localizados próximos a áreas dinâmicas como centros urbanos e subcentralidades, localizações privilegiadas em termos de acesso e por isso possibilitam a redução do gasto com transporte de famílias de baixa renda. A compactação acontece pelo fracionamento das unidades existentes, sem atendimento de regras urbanísticas, com aumento da densificação predial e familiar e a precarização da moradia. Os altos preços dos imóveis e aluguéis nestas APIs estimula muitas famílias a se mudarem para as franjas periféricas e ocupar os loteamentos clandestinos, ao mesmo tempo

\footnotetext{
2 ABRAMO (2009) define informalidade, referenciado Alegria (2005) como um conjunto de irregularidades em relação aos direitos: irregularidade urbanística, irregularidade construtiva e irregularidade em relação ao direito de propriedade da terra.
} 
em que, os altos custos de transporte e falta de acesso dos loteamentos estimula outras famílias a buscarem residência nessas APIs para reduzir assim os gastos com transporte. Esse duplo movimento de precarização da moradia, impõe desafios não apenas sociais, como ambientais e éticos.

A configuração espacial resultante dessa dinâmica de ocupação urbana que promove ao mesmo tempo a difusão do tecido urbano e a sua compactação através dos mercados formal e informal do solo, Abramo (2009) denominou cidade com-fusa.

Partindo então da reflexão sobre as cidades com-fusas, e considerando que as cidades não crescem apenas em processos difusos sobre o território, mas também se compactam, vamos explorar os aspectos que se relacionam às infraestruturas viárias e que podem contribuir para a reflexão sobre a dispersão urbana.

\section{DISPERSÃO URBANA}

Começaremos apontando alguns resultados dos estudos do grupo de pesquisa do professor Nestor Goulart (USP) sobre a dispersão urbana nas cidades brasileiras, que relaciona o fenômeno a mudanças sociais de grande envergadura. A primeira constatação é de que a dispersão urbana tende a ocorrer em áreas correspondentes às aglomerações metropolitanas e semimetropolitanas e ao redor dos núcleos isolados de maior porte com intensa concentração, que é ocaso de Manaus. Uma segunda evidência é de que a dispersão se dá em áreas onde ocorrem mudanças nas formas de produção e nas formas de consumo, com a adoção de modos de vida metropolitanos. Outro aspecto é que o processo vem acompanhado por inovações nos setores de transportes, comunicações e descentralização de atividades industriais, de comércio, serviços e de áreas residenciais. Goulart (2015) alerta ainda que a palavra "cidade" não é mais adequada para tratar a complexidade do fenômeno, já que define uma aglomeração urbana em contraposição à população que vive nos campos. A cidade em dispersão dilui esses limites. "O urbano é a regra, não a exceção" e a vida urbana invade o rural.

Voltando a Abramo $(2007,2009)$ e considerando a coordenação espacial promovida pelos mecanismos de mercado do solo urbano, adotamos alguns pontos de partida, ou hipóteses secundárias, de que a implantação de infraestruturas urbanas pode produzir fenômenos de dispersão de três maneiras: i) atraindo loteamentos clandestinos para zonas periurbanas; ii) atraindo inovações do mercado formal "externalidades de vizinhança" em zonas com apelo paisagístico, criando a repulsa por famílias de renda mais baixa, ou convenção urbana (Abramo, 2007); iii) dissolvendo o rural no modo de vida urbano.

Seguiremos então buscando um procedimento metodológico para análise da paisagem em transformação e explorando suas potencialidades.

\section{A PAISAGEM}

A paisagem enquanto conceito multidisciplinar, está sujeita a tensões investigativas. Por um lado, é uma prática de representação artística baseada na experiência sensorial frente ao observador, campo de estudo da arte e da filosofia; por outro, é um artefato geográfico, ou, uma área composta por uma associação distinta de formas, ao mesmo tempo físicas e culturais (Sauer, 1925).

Frente à velocidade das transformações da sociedade atual na era técnico-científica-informacional, (Santos, 2008) a noção de paisagem, não como um bem a recuperar ou proteger, mas como uma plataforma ou paradigma, possibilita compreender e operar territórios em transformação (Contenti e Recoba, 2013) .

Por paisagem entendemos um conjunto de formas que, num dado momento, exprime sucessivas relações entre o homem e a natureza (Santos, 2008). A palavra, também utilizada no sentido de configuração espacial, relaciona um "conjunto de elementos naturais e artificiais que fisicamente caracterizam uma área" (Santos, 2008. p. 103).

Considerada a sedimentação e interação permanente entre o meio natural e humano, campo da geografia e dimensão projetual (Tapia e Alvez, 2016), a paisagem escapa às definições e teorias absolutas, permitindo a aproximação do fenômeno urbano e sua interpretação como realidade aberta e em transformação. Ela reaparece com força na cultura contemporânea na qual existe uma crescente preocupação ambiental e ecológica, necessidade de manter identidade de regiões e de mensurar e gerir os impactos do crescimento disperso e difuso (García García e Borobio, 2012). A paisagem pode outorgar racionalidade a esses territórios metropolitanos, tornando-se um marco e um guia para o projeto do território (Vecina, 2014).

Santos (2008) faz uma importante distinção epistemológica entre paisagem e espaço. "Cada paisagem se caracteriza por uma dada distribuição de formas-objetos, providas de conteúdo técnico específico. Já o espaço resulta da intrusão da sociedade nessas formas-objetos" (Santos, 2008:103). Outro aspecto que diferencia a paisagem do espaço, além do seu caráter material é que ela é transtemporal e funciona como um palimpsesto, onde a história é constantemente escrita, borrada e reescrita- uma construção vertical. Já o espaço é o tempo presente, ou uma construção horizontal. Por isso as formas-objetos não mudam de lugar, 
mas de função, valor e significado. Um dos pressupostos da paisagem é de que ela é um sistema material, relativamente imutável, e o espaço, um sistema de valores, que muda constantemente.

A paisagem é considerada um instrumento de pesquisa que permite rever etapas do passado numa perspectiva de conjunto, uma vez que está imobilizada na matéria. No entanto, enquanto paisagem presente só pode ser compreendida quando confrontada com a sociedade atual. Pode-se também falar do funcionamento da paisagem, uma vez que é testemunha da sucessão dos meios de trabalho e um resultado histórico acumulado (Santos, 2008: 107). Por isso, a paisagem se apresenta como uma categoria de análise e um modelo para a interpretação e representação do espaço onde vários objetos se interrelacionam. Ela representa o tempo passado, ou paisagem consolidada; as necessidades emergentes, ou paisagem presente; e contem ou subjaz uma previsibilidade ou imprevisibilidade, uma paisagem perspectiva (Loures e Coelho, 2008).

A princípio a paisagem tem uma área determinada, que se pode abarcar com os olhos, embora, diferentes escalas aconteçam conforme o posicionamento do observador frente ao fenômeno físico. Mesmo admitindo que descrever uma paisagem possa ter uma validade limitada, pois é um exercício de generalização derivado da observação de cenas individuais, Sauer (1925) afirma que a paisagem constitui um todo que tem uma forma, uma estrutura e uma função e que tem relação direta com o tempo e o espaço. Ela está posicionada em um sistema maior e sujeita a mudanças e desenvolvimento. Esse desenvolvimento é bem elucidado por Santos (2008) quando atribui a ela a função de palimpsesto, "onde mediante acumulações e substituições, a ação das diferentes gerações se superpõe" (Sauer, 1925: 104). O que permanece do passado como forma e desvela o processo de supressão, acumulação e superposição, é o que Santos (2008) denomina: rugosidades.

A paisagem existe através das formas criadas em momentos históricos diferentes e os objetos técnicos que Ihe dão forma estão sempre à espera de conteúdo social. O conteúdo social é o que transmite vida à coisa, ou seja, que faz com que um objeto técnico abandone sua condição de simples tecnologia e se transforme em economia. Por isso, paisagem e sociedade são variáveis complementares, sintetizadas no espaço humano (Santos, 2008) ou na paisagem cultural (Sauer, 1925).

\section{A MORFOLOGIA URBANA}

A Morfologia Urbana tem relação direta com o estudo da paisagem e apesar de se referir à forma urbana ela se ocupa também da organização social do espaço. Ela propicia procedimentos para a descrição e comparação entre diferentes cidades com diferentes abordagens segundo grupos de autores e escolas, mas invariavelmente utiliza, para a análise da forma urbana, a arquitetura da cidade, o layout das ruas, e as diferentes densidades de habitação (Kropf, 2009). Ocupa-se do estudo do tecido urbano e seus elementos construídos através de sua evolução, transformações, inter-relações e dos processos sociais que os geraram.

A Morfologia Urbana considera a cidade como produto físico das ações da sociedade sobre o meio e edificada ao longo da história (Pereira Costa e Gimmler Neto, 2015). Na Morfologia Urbana há duas abordagens distintas, porém complementares, para a análise da estrutura formal da paisagem urbana. Um ponto de vista estritamente morfológico, concentrado na diversificação das formas visíveis, e um segundo, que se refere aos aspectos dinâmicos da sociedade que produz e altera a paisagem ao longo do tempo. Ou seja, um ponto de vista formal e uma análise temporal. (Pereira Costa e Gimmler Neto, 2015: 33).

Há certo consenso no estudo da forma urbana de que o processo de crescimento das cidades e a formação de seus tecidos ocorrem ao longo de vias e caminhos, naturais ou artificiais (Lynch, 1981; Panerai, 1999), ou surgem à partir da estruturação das rotas. $O$ crescimento tende a se acontecer no seio de um sistema complexo de conexões espaciais, o que envolve inevitavelmente uma rede regional, nacional e global na qual a cidade está inserida e pode ser interpretado a partir de dados relacionados à sua evolução histórica. Assim o crescimento urbano ocorre em um sistema complexo, no interior de uma rede. Quando horizontal o crescimento pode estar sujeito a obstáculos geográficos ou construídos que são as barreiras. Quando ocorre sem expansão territorial, dizemos que o crescimento se adensa dentro de um perímetro.

Das definições e princípios relacionados ao processo de análise da paisagem urbana são destacadas dois elementos reguladores: polo e eixos de expansão urbanos; e o seu resultante espacial: tecido urbano. A princípio, os polos são lugares singulares, pelo caráter de origem, local de concentração e carga simbólica (Panerai, 1999) e remetem à existência de interseções e congregação de atividades ao seu redor (Pereira Costa e Gimmler Neto, 2015). As linhas de crescimento, são elementos fundamentais na composição e estruturação do tecido urbano das cidades, sejam caminhos, vias, estradas, ou elementos naturais, como rios e canais fluviais.

As linhas de crescimento são o suporte de crescimento ao longo de uma direção, podem ser naturais, ou seja, presentes no território antes da urbanização, ou artificiais, projetadas e construídas (Panerai, 1999). O 
tecido urbano reúne os elementos edificados e não edificados definindo uma textura espacial. Ele é formado pela rede de vias, espaços livres, parcelamentos e edificações.

Moudon (2015) analisando contribuições dos estudos morfológicos difundidos pelo Internacional Seminar on Urban Form (ISUF) identifica três componentes fundamentais da investigação em morfologia urbana: i) A forma urbana é definida por três elementos físicos fundamentais: edifícios e os espaços abertos relacionados com estes, parcelas ou lotes, e ruas; ii) A forma urbana pode ser compreendida em quatro níveis de resolução: edifício/parcela, rua/quarteirão, cidade, e região; iii) A forma urbana só pode ser compreendida na sua dimensão histórica uma vez que os elementos que ela compreende sofrem uma contínua transformação e substituição.

A forma urbana se organiza em unidades de plano ou tecidos urbanos, que "são conjuntos de edifícios, espaços abertos, parcelas e ruas, formando um todo coeso, ou porque foram todos construídos num mesmo tempo ou com as mesmas condicionantes, ou porque sofreram um mesmo processo de transformação" (Moudon, 1997).

M. R. G. Conzen, introduziu na década de 1930 alguns princípios para a análise histórico-geográfica, como os períodos morfológicos e períodos evolutivos. E o conceito de região morfológica, ou unidades de plano, unidades de paisagem urbana ou ainda regiões de paisagem urbana - método de regionalização morfológica (Oliveira, 2018). Seu método de análise morfológica originou o que hoje é conhecida coo "escola inglesa" de morfologia urbana, que considera a estrutura tripartida da paisagem urbana e a existência de uma hierarquia de regiões, que depende não só da variedade de formas urbanas existentes na área de estudo, normalmente associada à existência de diferentes períodos temporais, mas também do detalhe com que a paisagem urbana é examinada (Oliveira, 2018).

Para Salat et. al. (2012) os componentes da morfologia urbana são estratificações de níveis que interagem entre si. O autor identifica e classifica seis níveis: i) pessoas e atividades e as interações sociais; ii) redes de ruas, estradas e canais de circulação; iii) parcelas de lotes; iv) topografia e relevo; v) usos do solo e atividades, enquanto aspecto decisivo de influencia sobre os fluxos de pessoas, energia e organização de edifícios; vi) ambiente construído e fatores climáticos.

Alguns temas e elementos para a pesquisa da Morfologia Urbana expõem as lógicas evolutivas e estruturadoras da cidade (Rossi, 1995; Panerai, 2006): i) crescimento: os modos, as intensidades e direções; elementos geradores e reguladores, limites e superação de limites, modificação de estruturas, pontos de cristalização etc.; ii) traçado e parcelamento: ordenadores do espaço, estrutura fundiária, relações, distâncias, circulação e acessibilidade; iii) tipologias dos elementos urbanos: inventário e categorização de tipologias edilícias (residências, comércio etc.) de lotes e sua ocupação, de quarteirões e sua ocupação, de praças, esquinas etc.; iv) articulações: relações entre elementos, hierarquias, domínios do público e privado, densidades, relações entre cheios e vazios etc.

A descrição geral da forma de um aglomerado populacional, segundo argumenta Kevin Lynch em sua "Teoria Normativa" para a boa forma urbana (Lynch, 1981), deve considerar duas classes de características físicas: "as pessoas em ação e as instalações físicas que servem de suporte a essas ações." (Lynch, 1981, p. 329). Pessoas podem ser divididas em: 1) Pessoas ativas a nível local - trabalhar, ensinar, jogar, falar; 2) Pessoas em trânsito. Enquanto as instalações podem ser divididas em: 1) Espaços adaptados - recintos, volumes modificados para receber atividades, melhoramentos no terreno, equipamentos; 2) Sistemas de fluxos - canais, estradas, ruas e veículos.

\begin{tabular}{|c|c|c|}
\hline AUTORES/ESCOLAS & $\begin{array}{l}\text { FORMA URBANA É DEFINIDA } \\
\text { POR... }\end{array}$ & ELEMENTOS REGULADORES \\
\hline $\begin{array}{l}\text { Lynch } \\
\text { Vertente cognitiva e normativa }\end{array}$ & $\begin{array}{l}\text { Pessoas em ação - pessoas ativas } \\
\text { em nível local e pessoas em trânsito; } \\
\text { Instalações físicas - Espaços } \\
\text { adaptados e sistemas de fluxos }\end{array}$ & $\begin{array}{l}\text { Vitalidade } \\
\text { Sentido } \\
\text { Adequação } \\
\text { Acesso } \\
\text { Controle } \\
\text { Eficiência } \\
\text { Justiça }\end{array}$ \\
\hline $\begin{array}{l}\text { Salat, Adolph Lukas } \\
\text { Resiliência urbana e sustentabilidade }\end{array}$ & $\begin{array}{l}\text { Pessoas e atividades e as interações } \\
\text { sociais; } \\
\text { Redes de ruas, estradas e canais de } \\
\text { circulação; } \\
\text { Parcelas de lotes; } \\
\text { Topografia e relevo; } \\
\text { Usos do solo e atividades }\end{array}$ & $\begin{array}{l}\text { Os componentes da morfologia } \\
\text { urbana são estratificações de níveis } \\
\text { que interagem entre si }\end{array}$ \\
\hline $\begin{array}{l}\text { Panerai, Castex } \\
\text { Escola Francesa }\end{array}$ & $\begin{array}{l}\text { Rede de vias; } \\
\text { Parcelamentos fundiários; } \\
\text { Edificações }\end{array}$ & $\begin{array}{l}\text { Elementos que organizam a } \\
\text { expansão: linhas e polos; } \\
\text { e aqueles que a contém: barreiras e }\end{array}$ \\
\hline
\end{tabular}




\begin{tabular}{|c|c|c|}
\hline & & limites \\
\hline $\begin{array}{l}\text { Conzen, Whitehand, outros } \\
\text { Vertente histórico-geográfica } \\
\text { "Escola inglesa" }\end{array}$ & $\begin{array}{l}\text { Plano (sistemas de ruas, sist. } \\
\text { parcelas, sist. de edifícios), } \\
\text { Tecido (volume edificado) } \\
\text { Uso do solo }\end{array}$ & $\begin{array}{l}\text { Região morfológica: Período } \\
\text { morfológico } \\
\text { Fringe belts (“cinturas periféricas”) } \\
\text { Efeito de vizinhança. }\end{array}$ \\
\hline $\begin{array}{l}\text { Hiller, Hanson, Batty } \\
\text { Vertente configuracional }\end{array}$ & $\begin{array}{l}\text { Rede } \\
\text { Orientação, } \\
\text { Distância, } \\
\text { Posição, } \\
\text { Conectividade }\end{array}$ & $\begin{array}{l}\text { Linhas, } \\
\text { trechos e } \\
\text { nós }\end{array}$ \\
\hline
\end{tabular}

Colaborações da Morfologia Urbana

Elaboração própria

\section{PAISAGEM URBANA COMO CATEGORIA ANALÍTICA}

De modo a garantir uma análise do território enquanto produto de uma sociedade, um projeto a serviço de estratégias, e enquanto forma, a pesquisa incorpora procedimentos de investigação da morfologia urbana ao estudo da paisagem. A paisagem, assim com a morfologia urbana, se ocupa dos objetos técnicos, da cidade construída e de seus processos de crescimento, os quais envolvem as práticas sociais. Assumindo o posicionamento de alerta de Lefebvre (1972) quanto ao perigo de se deixar seduzir pelo projeto e pela forma, uma vez que o espaço instrumental oculta estratégias e está a serviço do poder, acreditamos que a paisagem nos fornece uma plataforma oportuna para a intervenção no território enquanto prospecção formal e significativa. Pois, ao distinguir forma e processo e incorporar a matriz biofísica à análise qualitativa do ambiente possibilita outra perspectiva sob o território, ampliando a gama de elementos explicativos e analíticos ao processo de produção do espaço.

A adoção da paisagem enquanto categoria analítica permite assim, em primeira instância: i) apreensão do visível-sensível como produção social; ii) identificação do conjunto de elementos naturais e artificiais que fisicamente caracterizam o território iii) comparação temporal e iv) representação de processos sobrepostos utilizando dispositivos como mapas, imagens e narrativas ; e v)fomentar ações propositivas sobre o território a nível de projeto urbano. Os quadros abaixo demonstram: a) comparação entre diferentes abordagens e critérios para a análise da paisagem, e b) critérios definidos pelas autoras para a análise da paisagem da urbanização dispersa.

\begin{tabular}{|c|c|c|}
\hline FONTE/AUTOR & $\begin{array}{c}\text { CRITÉRIOS PARA ANÁLISE DA } \\
\text { PAISAGEM }\end{array}$ & ABORDAGEM \\
\hline SAUER (1925) & $\begin{array}{l}\text { - Elementos naturais } \\
\text { - Extensividade (área) } \\
\text { - Significado - caráter } \\
\text { - Equivalência funcional } \\
\end{array}$ & $\begin{array}{l}\text { - Fatos Morfológicos: paisagem natural } \\
\text { e paisagem cultural } \\
\text { - Cartografia - mapa } \\
\text { - }\end{array}$ \\
\hline GREGOTTI (2004 [1972]) & $\begin{array}{l}\text { - Conjunto de elementos dentro de um } \\
\text { campo: estratos e seções } \\
\text { - Polaridades, } \\
\text { - Sequências geométricas, } \\
\text { - Tipo de malha, } \\
\text { - Densidade de significado }\end{array}$ & $\begin{array}{l}\text { Escalas: } \\
\text { - Geográfica - sobre o território; } \\
\text { - Topográfica - sobre o circunstante; } \\
\text { - Objeto }\end{array}$ \\
\hline SANTOS (2008) & $\begin{array}{l}\text { - Forma-conteúdo, } \\
\text { - Rugosidades, } \\
\text { - Eventos. }\end{array}$ & $\begin{array}{l}\text { - Sistema de objetos e sistema de } \\
\text { ações }\end{array}$ \\
\hline LOURES e COELHO (2008) & $\begin{array}{l}\text { - Texturas, } \\
\text { - Formas naturais e artificiais; } \\
\text { - Valores simbólicos; } \\
\text { - Tensões e (in)tenções sociais; } \\
\text { - Formas de crescimento }\end{array}$ & $\begin{array}{l}\text { - Paisagem consolidada (rugosidades) } \\
\text { - Paisagem presente } \\
\text { - Perspectiva de paisagem futura }\end{array}$ \\
\hline VECINA (2014) & $\begin{array}{l}\text { - Camadas, } \\
\text { - Espaços livres, } \\
\text { - Fronteiras e } \\
\text { - Processos } \\
\end{array}$ & $\begin{array}{l}\text { - Identidade natural } \\
\text { - Análise histórica } \\
\text { - Forças culturais, sociais e econômicas } \\
\text { - Diferentes escalas - flutuar o olhar } \\
\end{array}$ \\
\hline TARDIN (2010) & $\begin{array}{l}\text { - Espaços livres } \\
\text { - Espaços ocupados } \\
\text { - Todo sistêmico } \\
\end{array}$ & $\cdot$ \\
\hline
\end{tabular}




\begin{tabular}{l|l|l}
\hline Laboratório QUAPÁ/USP & $\begin{array}{l}\text { - Sistema de Espaços Livres (SEL) } \\
(2015)^{3}\end{array}$ & \\
& $\begin{array}{l}\text { - Tipo morfológicos } \\
\text { - Agentes }\end{array}$ & \\
\hline
\end{tabular}

Quadro de critérios de analise da paisagem segundo diversos autores

Elaboração própria

\begin{tabular}{|c|c|c|c|}
\hline CATEGORIAS & CARACTERÍSTICAS & $\begin{array}{l}\text { ELEMENTOS } \\
\text { CAMADAS }\end{array}$ & ESCALAS \\
\hline Sistemas de fluxos & $\begin{array}{l}\text { Rede viária, canais } \\
\text { navegáveis, infraestruturas }\end{array}$ & $\begin{array}{l}\text { Eixos e linhas de } \\
\text { crescimento }\end{array}$ & $\begin{array}{l}\text { Nacional, regional, } \\
\text { local }\end{array}$ \\
\hline Polos/centralidades & $\begin{array}{l}\text { Zonas de especial interesse } \\
\text { simbólico e econômico }\end{array}$ & $\begin{array}{l}\text { Pontos e manchas } \\
\text { imagens e narrativas }\end{array}$ & $\begin{array}{l}\text { Nacional, regional, } \\
\text { local }\end{array}$ \\
\hline Ambiente construído & $\begin{array}{l}\text { Edificações, lotes e seus } \\
\text { arranjos espaciais. }\end{array}$ & $\begin{array}{l}\text { Unidades morfológicas: } \\
\text { edificações, lotes, } \\
\text { arranjos }\end{array}$ & Regional, Local \\
\hline $\begin{array}{l}\text { Sistema de espaços } \\
\text { livres }\end{array}$ & $\begin{array}{l}\text { Ruas, praças, parques e } \\
\text { espaços públicos, áreas de } \\
\text { preservação, suporte físico }\end{array}$ & $\begin{array}{l}\text { Manchas - linhas } \\
\text { bordas }\end{array}$ & Regional, Local \\
\hline Agentes & $\begin{array}{l}\text { Estado, mercado, } \\
\text { sociedade civil }\end{array}$ & $\begin{array}{l}\text { Intervenções, } \\
\text { loteamentos tipologias }\end{array}$ & Regional, local \\
\hline Normas e Leis & $\begin{array}{l}\text { Leis urbanas e ambientais, } \\
\text { planos. }\end{array}$ & $\begin{array}{l}\text { Zoneamentos, planos e } \\
\text { projetos }\end{array}$ & $\begin{array}{l}\text { Nacional, regional, } \\
\text { local }\end{array}$ \\
\hline
\end{tabular}

Quadro de critérios elencados pelas autora para a análise da paisagem

Elaboração própria

A análise da paisagem deve ser realizada de maneira multiescalar. Na escala regional e metropolitana é possível entender as principais conexões, e as formas naturais do território e na escala intra-urbana podemos analisar a forma das cidades, padrões e agentes. Em ambas as escalas o território deve ser analisado enquanto: i) produto, através da atuação dos agentes: Estado, mercado e sociedade civil; ii) projeto, a partir da interpretação das leis, normas, projetos, estratégias; iii) forma, por meio da análise dos espaços físicos construídos e naturais.

Como já mencionado, o artigo é parte de uma pesquisa maior em desenvolvimento, por isso, a análise crítica realizada a seguir possui caráter exploratório e considera o avanço da pesquisa até o momento. Em função do espaço disponível para demonstração dos resultados, nos limitaremos aos aspectos globais considerados essenciais para a conclusão a respeito do território enquanto produto, projeto e forma, não sendo possível explorar cada uma das categorias elencadas no quadro 01.

\section{PAISAGEM URBANA MANAUS EM PROCESSO DE METROPOLIZAÇÃO}

Manaus representa um importante nó na rede urbana brasileira, e desempenha forte influência na região Amazônica, sendo por isso considerada uma Metrópole. Ela controla uma das redes de maior área, 19\% da área do País, e de menor densidade, 2,2 hab. $/ \mathrm{km}^{2}$ (IBGE, 2008). Os municípios que compõem a Região Metropolitana de Manaus (RMM) ${ }^{4}$ possuem extensas dimensões territoriais, o que traz feições continentais ao conjunto com $127.119 \mathrm{~km}^{2}$. O polo principal, Manaus, possui hoje, cerca de 2 milhões de habitantes enquanto que nos demais municípios da RMM a população total não chega a 100 mil habitantes (IBGE, 2010). O conjunto enfrenta problemas como a dispersão do tecido urbano e a redução do acesso dos cidadãos aos bens, serviços e espaços públicos, além disso, apresenta elevados índices de pobreza e desigualdade social.

\footnotetext{
${ }^{3}$ Oficinas do grupo de pesquisas QUAPÁ/ SEL da USP realizado na cidade de Manaus ano de 2015

${ }^{4}$ A institucionalização da Região Metropolitana de Manaus (RMM) aconteceu a partir de uma ação política - Lei Complementar Estadual no 052 de 30 de maio de 2007. A princípio a RMM era constituída por 08 municípios: Manaus, Iranduba, Careiro da Várzea, Novo Airão, Presidente Figueiredo, Rio Preto da Eva, Itacoatiara e Manacapuru. Hoje conta com mais 5 municípios: Autazes, Careiro Castanho, Itapiranga, Manaquiri e Silves.
} 


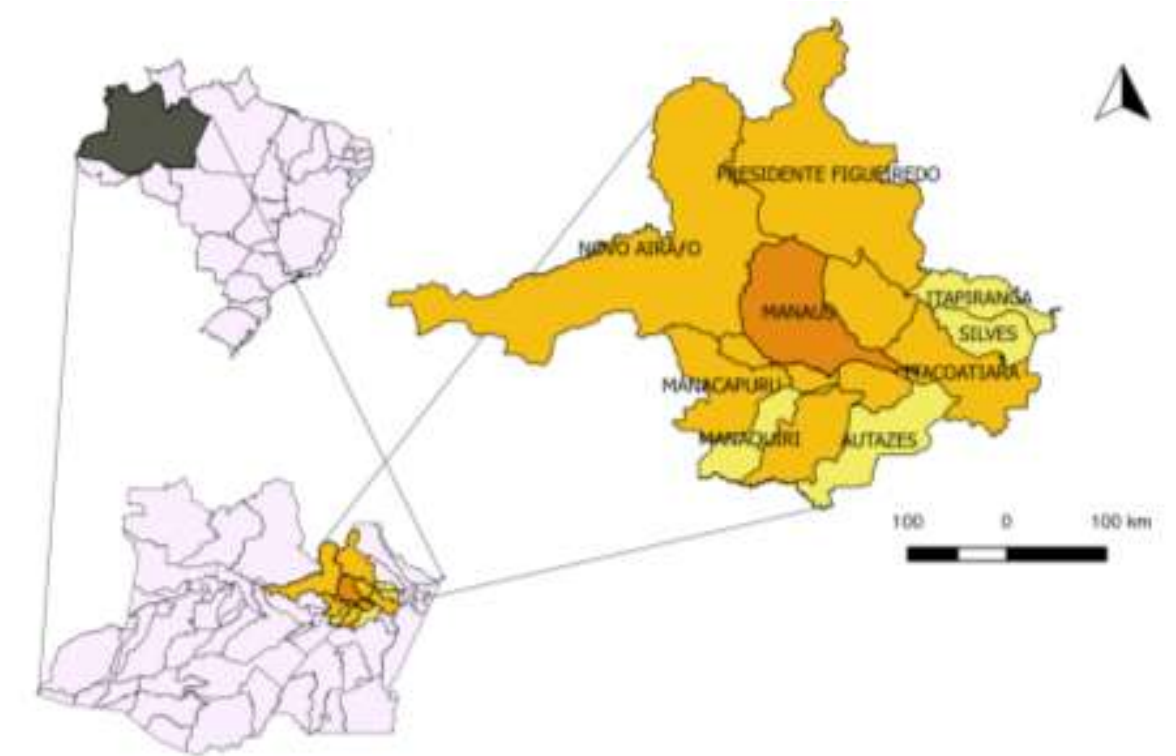

Localização Região Metropolitana de Manaus

Elaboração própria

A ponte sobre o rio Negro inaugurada em 2011 legitima a Região Metropolitana instituída por lei. O objetivo de sua construção, segundo o Governo do Estado, seria permitir a integração entre a Região Metropolitana de Manaus (RMM) e demais regiões como Purus e Médio e Alto Solimões, e favorecer o deslocamento de pessoas e produção agrícola dos Municípios de Iranduba, Manacapuru e Novo Airão. Concomitante à implantação da ponte foi elaborado um plano diretor para a RMM, o qual não foi levado à votação na Assembleia legislativa do Estado do Amazonas. Foi elaborado também um Plano Urbanístico para a ocupação da Margem Direita, que definia o uso e ocupação do solo no município de Iranduba. Esse plano foi enviado para votação na câmara dos vereadores do município de Iranduba, no entanto sua aprovação até hoje não foi efetivada.

Às margens de qualquer normativa municipal sobre o seu território e tendo a ponte como símbolo de desenvolvimento, Iranduba se tornou palco de novas formas de ocupação movidas pelo mercado formal e informal do solo. A dinamização desse mercado do solo desponta na paisagem em grandes loteamentos e conjuntos habitacionais, ocupações subnormais e fracionamento de propriedades rurais. A proposta de implantação de um novo campus da Universidade Estadual do Amazonas - UEA ${ }^{5}$ pelo governo estadual catalisa ainda mais essa dinâmica e impulsiona a ocupação especulativa no seu entorno.

\footnotetext{
${ }^{5}$ O projeto do campus contempla 120 mil hectares às margens do rio Negro e, além das dependências da Universidade, abrigará outros usos como residencial e de apoio ao turismo como hotéis e resort.
} 


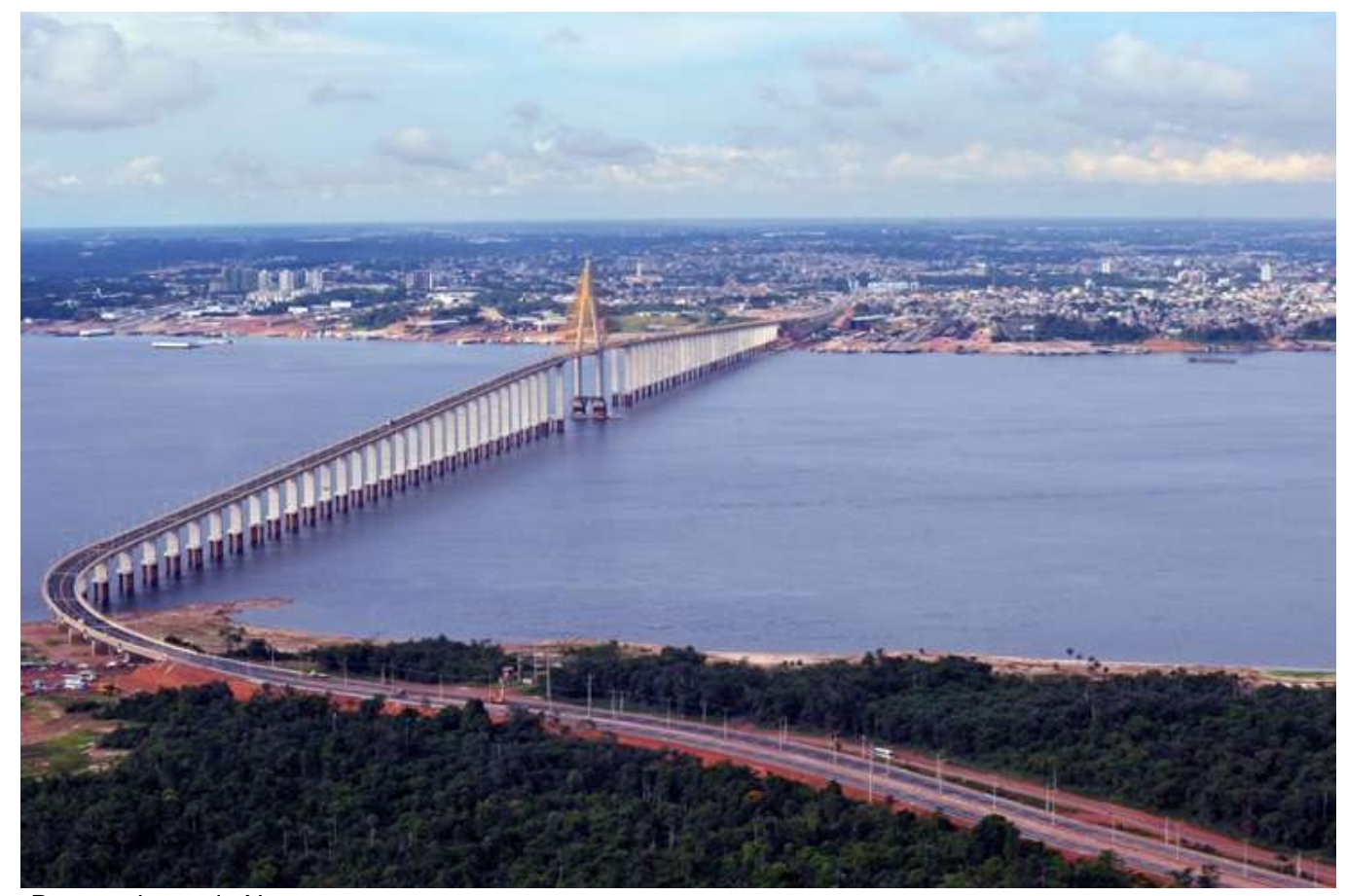

Ponte sobre o rio Negro

Fotografia de Chico Batata

Até a inauguração da ponte o trajeto Manaus-Iranduba era feito por balsa mais transporte rodoviário ônibus ou carro. Após a ponte o deslocamento é realizado em poucos minutos. Assim, vende-se o acesso à Manaus, pois o território rural de Iranduba e o distrito de Cacau Pirera, agora são quase um bairro central de Manaus.

O centro de Manaus, apesar da consolidação de outros subcentros nas Zonas Leste e Norte, é ainda o centro primaz, concentrando empregos, comercio e serviços, além de ser a principal porta de entrada para embarcações de passageiros e produtos do interior do estado. $O$ centro de Manaus e os bairros que o circundam, apresentam alta densidade construída. O que faz com que o solo em suas proximidades seja cada dia mais valorizado.

\section{NA OUTRA MARGEM DO RIO....}

A gênese da ocupação urbana de Iranduba e Manacapuru tem relação direta com o acesso via fluvial pelo rio Solimões, às margens do qual os núcleos urbanos se desenvolveram.

A ponte estimula uma nova configuração espacial à medida que favorece o acesso rodoviário ao centro de Manaus e aos bairros da Compensa e São Raimundo, que abrigam respectivamente palácio do Governo do Estado e Câmara Municipal de Manaus. Assim, sob a influência da ponte e da duplicação da rodovia AM070, são engendrados processo de ocupação urbana nas áreas que fornecem melhor acesso a Manaus. Esse movimento introduz dois eixos de expansão urbana em sentidos opostos e complementares, que em médio a longo prazo, tendem a fortalecer a urbanização de zonas rurais localizadas entre a sede de Iranduba e Manaus. O primeiro eixo, no sentido Manaus-Iranduba, sobre a nova franja periférica nas proximidades de Cacau Pirera; e outro eixo, forçado o movimento centrífugo do núcleo urbano original de Iranduba em direção a AM-070, forçando a extensão de seus limites urbanos na direção oposta, sentido Iranduba-Manaus. 


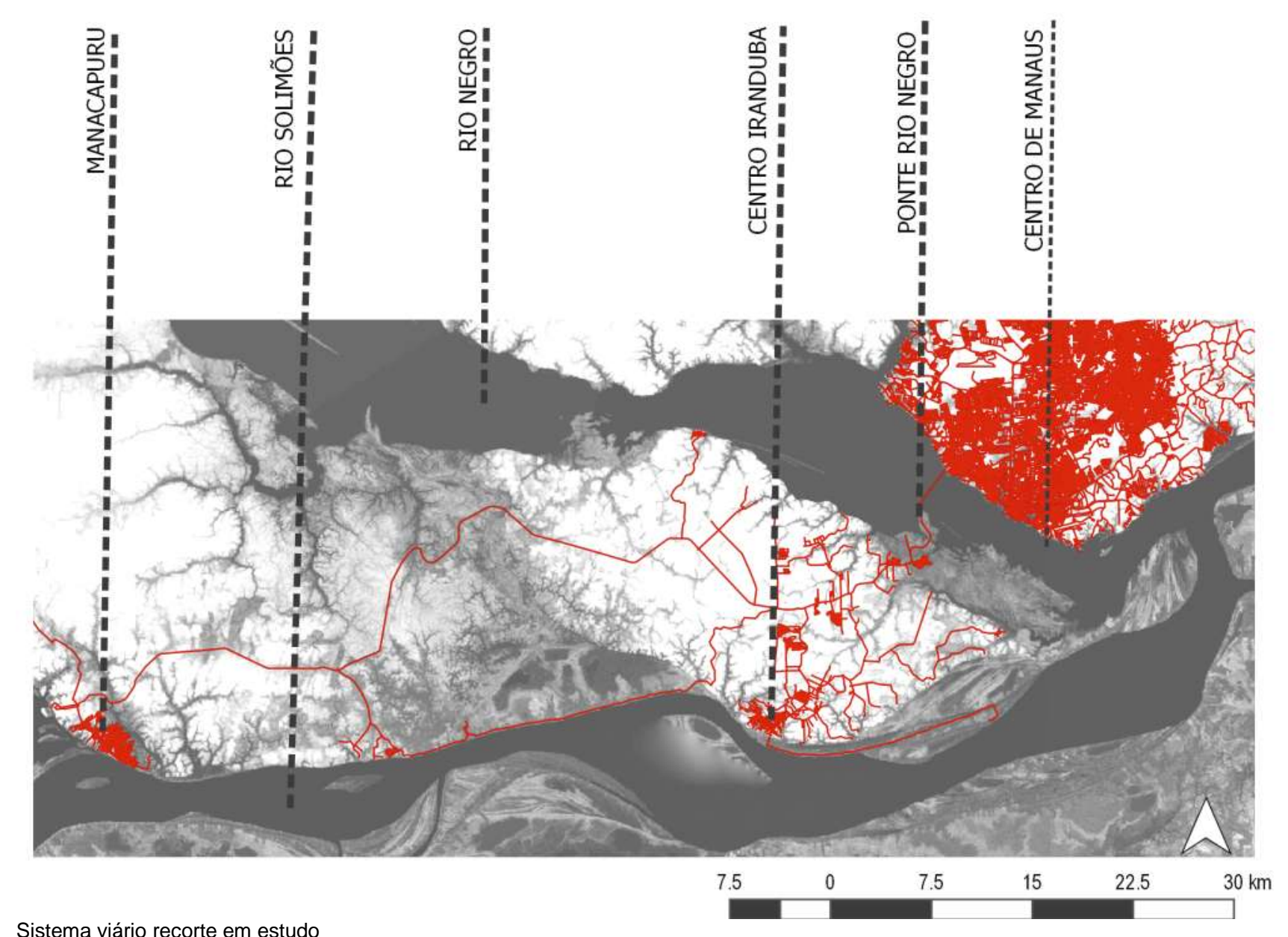

Sistema viário recorte em estudo

Elaboração própria sobre imagens SRTM (USGS)

Os veículos de comunicação de Manaus têm noticiado regularmente sobre agressões e mortes em consequência de conflitos por terra em Iranduba. A rápida valorização da terra atraiu grileiros e empresários, que frequentemente entram em conflito com as comunidades rurais ali estabelecidas e com órgãos federais como o Instituto Nacional de Colonização e reforma Agrária (INCRA). Em consequência dessa valorização das terras ocorre, em paralelo, um forte processo de desmatamento e de desmembramento de unidades agrárias para uso urbano.

\section{NÚCLEOS URBANOS CONSOLIDADOS E O PROCESSO DE DISPERSÃO URBANA}

A vida no interior do Amazonas, especialmente em Iranduba e Manacapuru é regulada pelos ciclos dos rios. A interação com esse elemento define a forma de ocupação e a tipologia construtiva da maioria dos municípios no estado. Além do núcleo principal, essas cidades também possuem distritos, comunidades rurais, assentamentos do INCRA e zonas rurais tanto na terra firme quanto nas áreas de várzea. $\mathrm{O}$ acesso fluvial predominou nos municípios em estudo até a inauguração da ponte e sua influencia pode ser percebida na morfologia urbana dos sítios consolidados, ou sedes dos municípios.

A localização do município, entre os rios Negro e Solimões, permite a existência de dois ecossistemas diversos. Na orla do Rio Negro "figuram paisagens paradisíacas, praias, cachoeiras e florestas abundantes; ao longo do rio Solimões descortinam-se extensas áreas de várzea com atividades agrícolas, pesqueiras e de contemplação." Iranduba é também o município amazonense com maior número de sítios arqueológicos registrados. São 100 no total. O município é constituído do núcleo urbano principal mais 5 distritos: Ariaú, Cacau Pirêra, Lago Limão e Paricatuba (IBGE, 2018).

A polaridade exercida pelo núcleo urbano de Iranduba vem perdendo sua força em função da velocidade com que novos estabelecimentos comerciais e de serviços vêm sendo implantados ao longo da rodovia AM070. O núcleo não está localizado na beira da rodovia, mas na beira do rio Solimões.

O ambiente construído é de tal maneira disforme e sem contornos que é difícil distinguir o rural e o urbano. Utilizando como parâmetro o tamanho mínimo do Módulo Rural, de 1 hectare, foi realizada classificação visual por dimensões de lotes em base georeferenciada utilizando o software livre Quantum Gis sobre 
imagens aéreas do Google, para identificação das áreas em processo de urbanização. Assim, foram identificadas as seguintes unidades morfológicas de ocupação urbana: i) núcleo urbano consolidado; ii) comunidade rural e distritos consolidados; iii) loteamentos residenciais (vazios e em processo de ocupação); iv) zonas rurais em processo de loteamento; e iv) lotes institucionais e industriais de grandes dimensões.

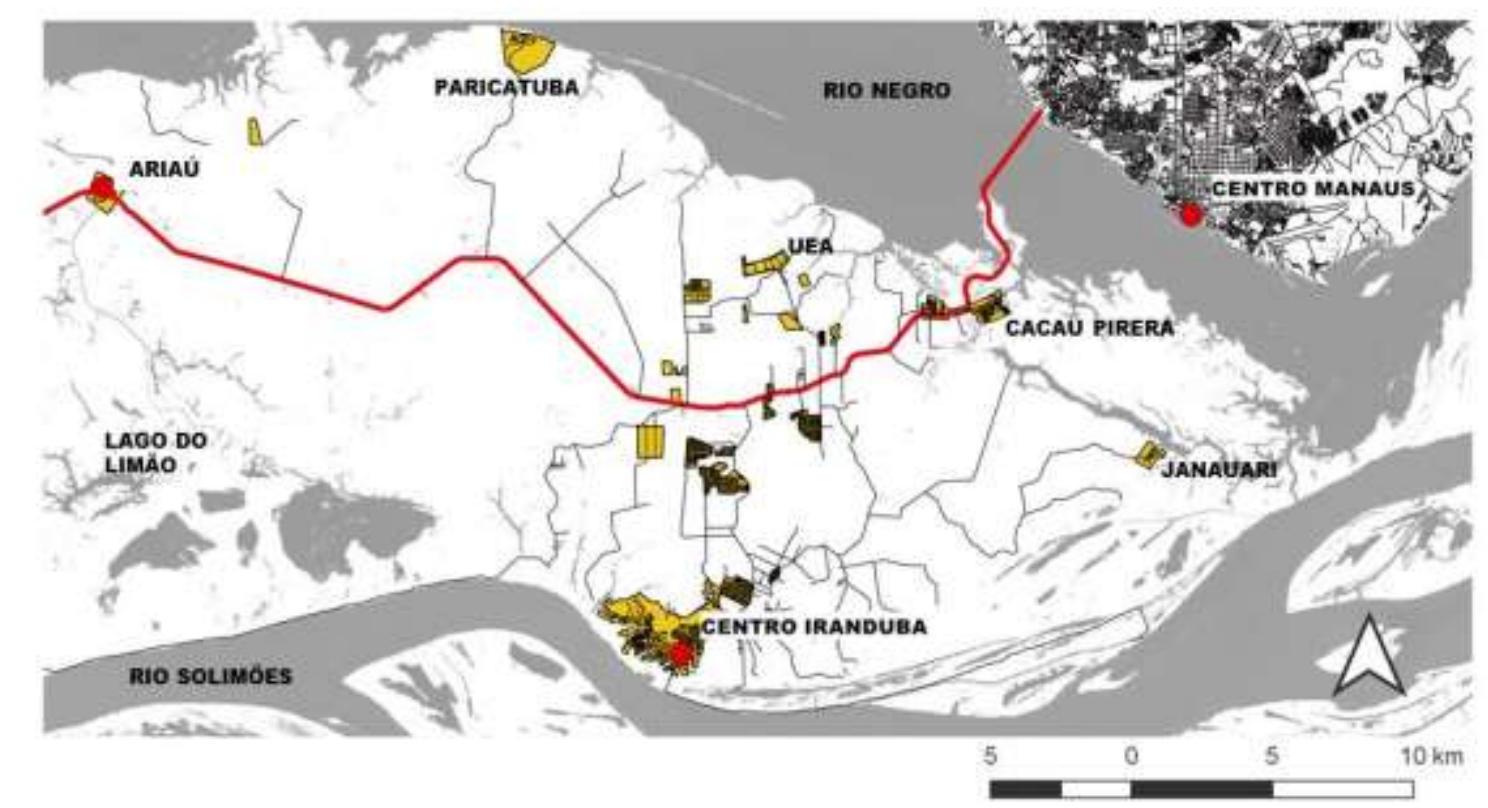

Áreas urbanizadas no município de Iranduba Elaboração própria

\section{CONCLUSÕES}

A afirmação de lógicas capitalistas na produção da espacialidade urbana coloca em evidência contradições entre os investimentos públicos em infraestrutura urbana e os fluxos de mais-valia gerados por elas, uma vez que colaboram para a valorização da terra e para a criação de estoques fixos de capital. As formas que a cidade adquire nesse processo, seja pela regulação normativa ou espontaneamente, evidenciam conflitos sociais no processo de apropriação do território pelos agentes.

Manaus é um desafio para os estudiosos do urbanismo, por um lado, porque sua situação geográfica contribui para que exerça forte influencia regional, porém, em dimensões muito diferentes do restante da rede urbana brasileira. Por outro lado, a economia baseada na indústria e no setor terciário atribui à capital do Amazonas feições metropolitanas atípicas. A baixa densidade de sua rede urbana, mesmo a de influencia direta da área Metropolitana, confere ao conjunto aspecto de ocupação difusa marcada por fortes desigualdades e hetereogeneidade no acesso aos benefícios e ônus da urbanização. Manaus dificilmente se encaixa em alguma teoria espacial de estudo das metrópoles.

O descompasso entre a implantação infraestruturas urbanas e a falta de controle sobre o processos de ocupação do solo e mudanças de uso delas advindos, ou por elas engendrados conduzem a processos de ocupação urbana que tendem à indeterminação e descontrole, principalmente quando novas peças de sistema viário avançam sobre zonas rurais e de floresta. Se, por um lado, o planejamento urbano se vale de princípios gerais de desenvolvimento sustentável e justiça social para estabelecer suas diretrizes de ocupação do solo, por outro, o processo real de ocupação do território reflete a precarização da esfera pública e da paisagem, com consequências de ordem ecológica e humana.

A forma física, variável dotada de inércia e fundamental para o exercício do planejamento territorial, pode ser desvelada pela leitura da paisagem, mas não é dotada de poder de provocar mudanças na sociedade. Apesar de não possuir o poder de provocar mudanças na sociedade, a sua compreensão pode contribuir para clarificar os conflitos existentes na apropriação do espaço pelos diferentes agentes, fornecendo subsídios para a previsão do impacto de ações de planejamento urbano (urbanismo) e projeto urbano (arquitetura). Sua manipulação por meio de estratégias de intervenção pode contribuir para a construção de novos cenários e fornecer subsídios para a formação de coesão social em torno das estratégias de desenvolvimento sustentado.

Planejar ou projetar esses territórios impõe o desafio de entender os processos naturais e artificiais a que as aglomerações humanas estão subordinadas e também evidenciar estratégias ideológicas de intervenção.

A intervenção estatal sem planejamento adequado favorece a expansão desordenada ameaçando os ecossistemas locais e os direitos sociais básicos. A ponte e a rodovia, limitadas à mera construção 
infraestrutural consolida uma postura racionalista e instrumental, não favorecendo o desenvolvimento sustentável. Ela vem fortalecer o modelo desenvolvimentista de décadas anteriores e impor sob a aparente racionalidade técnica uma estratégia de poder do Estado e do mercado imobiliário a ele solidário. A população de baixa renda assentadas em comunidades tradicionais e /ou rurais estão em processo de desterritorialização.

A rodovia AM-070 aliada à ponte conformam uma linha de crescimento de tamanha força que promovem 0 esvaziamento de significado do polo sede do município de Iranduba. A dinâmica ainda inicialk de dispersão do tecido urbano em duplo sentido Manaus-Iranduba e Iranduba-Manaus, parece sinalizar para uma futura conturbação entre áreas urbanas.

Considerando a complexidade desses territórios periféricos difusos e a excepcionalidade da Região Metropolitana de Manaus, a paisagem foi interpretada como uma categoria capaz de nortear novas oportunidades de intervenção, uma vez que possibilitou o desenvolvimento de análise teórica de suporte propositivo para a intervenção em territórios, ecossistemas, redes e infraestruturas. A paisagem foi capaz de fornecer subsídios para a interpretação do território enquanto produto, projeto e forma em múltiplas escalas..

\section{REFERÊNCIAS BIBLIOGRÁFICAS}

ABRAMO, P. (2007). A cidade caleidoscópica: coordenação espacial e convenção urbana, uma perspectiva heterodoxa para a economia urbana. Rio de Janeiro: Bertrand Brasil.

ABRAMO, P. (2009). A cidade com-fusa: a mão invisível do mercado e a produção da estrutura urbana nas grandes metrópoles latino-americanas. Em: Revista Brasileira de Estudos Urbanos e Regionais, vol.09, n.02, novembro de 2009. Disponível em <http://www.anpur.org.br/revistas/rev_ANPUR_v9_n2.pdf>. Acessado em novembro de 2016.

ALLEN, S. (1999). Infraestructural urbanism. Em: Ponts and Lines: Diagrams and projetcts for the city, Princetown Architectural Press, Nova York,. pp. 46-57. Tradução para espanhol de Alex Gim'nez Imirizaldu.

BAUMAN, Z. (2003). Modernidad Líquida. Tradução Mirta Rosenberg em colaboração com Jaime Arrambide Squirru. Buenos Aires: Fondo de Cultura Econômica Argentina S. A.

CASTELLS, M. (2000). A sociedade em rede. Vol I. Tradução R. V. Majer. São Paulo. Paz e Terra.

CONTENTI, L. e RECOBA A. (2013) Fluido y fragil: infraestructura y paisaje en territorios en transformación. Revista R11 - ISSN: 1688-9703.

CORBOZ, A. (1983). El território como palimpsesto. Diógenes, 121, enero-marzo 1983, pp. 14-35.

ELINBAUM , P. (2012). Una relación renovada entre el plan y el proyecto. Revista Iberoamericana de Urbanismo no7. Miradas Intencionadas. pp. 117-137.

GARCÍA GARCÍA, M. e BOROBIO S. M. (2012). El paisaje como medio para la planificación territorial. Ciudades 15 (1) 2012: 115-132. Universidad de Valladolid, Instituto de Urbanística.

GREGOTTI, Vittorio. (2004). Território da Arquitetura. Tradução Berta Waldman e Joan Villa. 3aㅡ ed. São Paulo: Perspectiva.

KROPF, K. (2009). Aspects of urban form. Urban Morphology Research Group, University of Birmingham and Roger Evans Associates Ltd, 59-63 High Street, Kidlington, OX5 2DN, UK. Revised version received 23.

LEFEBVRE, H. (1972). Espacio y política: el derecho a la ciudad II. Tradución: Janine Muls de Llarás y Jayme Llarás García. Madrid: Ediciones Península. 
LOURES, M. F. e COELHO, G. (2008) Paisagem revelada: possibilidades morfológicas nas favelas do Rio de Janeiro. Oculum Ensaios: Revista de Arquitetura e Urbanismo, n. 7-8,. pp. 110-121.

LYNCH, K. (1981) A boa forma da cidade. Tradução José Manuel Costa Almeida e Pinho. Lisboa/Portugal: Edições 70.

MENESES, P. R. e ALMEIDA, T. (orgs). (2012). Introdução ao processamento de Imagens de Sensoriamento Remoto. Brasília: UnB e CNPq.

MOUDON, A. V. (1997). Urban morphology as an emerging interdisciplinary field. In: Urban Morphology n. 1 , p. 3-10.

NORBERG-SCHULZ, C. (1980). Genius Loci: Towards a Phenomenology of Architecture. New York: Rizzoli International Publications. p. 5-48.

OLIVEIRA, V.(ed.). (2018). Diferentes abordagens em morfologia urbana. Contributos luso-brasileiros. E-book. Disponível em: <vitoroliveira.fe.up.pt>. Acesso em fevereiro de 2018.

PANERAI, P. R. (1999). Análise urbana. Brasília: EdUnB.

PANIZZA, A. C. e FONSECA, F. P. (2011). Técnicas de Interpretação Visual de Imagens. GEOUSP Espaço e Tempo, São Paulo, № 30, pp. 30 - 43.

PEREIRA COSTA, S. A. e GIMMLER NETO, M. M. (2015). Fundamentos de morfologia urbana. Belo Horizonte: C/Arte.

REIS, N. G. org. (2009). Sobre Dispersão Urbana. 1ª ed, São Paulo: Via das Artes.

REIS, N. G. org. (2015). Urbanização difusa. Revista Cidades. V. 12, oo 21 [revista on line]. Disponível em: <http://revista.fct.unesp.br/index.php/revistacidades/issue/view/285/showToc>. Acesso em dezembro de 2017.

ROSSI, A. (1995). A arquitetura da cidade. São Paulo: Martins Fontes.

SALAT, S.; LABBÉ, F.; NOWACKI, C. (2011). Citys and forms: on sustainable urbanism. Urban Morphology Laboratory. Hermann Éditeurs des sciences et des arts.

SANTOS, M. (2008). A natureza do espaço: técnica e tempo, razão e emoção. $4^{a}$ Ed. São Paulo: Editora da Universidade de São Paulo.

SAUER, C. O. (1925). A morfologia da paisagem. Publicado originalmente: "The morphology of landscape", University of California, Publications in Geography, vol. 2, $n^{\circ} 2,1925$, pp. 19-54. Traduzido por Gabrielle Corrêa Braga, bolsista CNPq/UERJ. Revisão de Roberto Lobato Corrêa, Departamento de Geografia, UFRJ.

SECCI, B. (2015). Primeira lição de urbanismo. Tradução: Maria Barda e Pedro M. R. Sales. São Paulo: Perspectiva.

SENNETT, R. (2014). Léspai públic: um sistema obert, um procés inacabat. Traducció Marina Espasa. Barcelona: Arcadia. 
SPOSITO, M. E. B. (1994). Urbanização difusa e cidades dispersas: perspectivas espaço-temporais contemporâneas. In: SANTOS, M., SOUZA, M.A.S. e SILVEIRA, M.L. (org.) Território: Globalização e Fragmentação. São Paulo: Hucitec - ANPUR.

TAPIA, C. e ALVES, M. R. (2016). Townscopes y Contra Paisajes, cuestiones de un urbano contemporáneo Revista Risco: revista em arquitetura e urbanismo do Instituto de Arquitetura e Urbanismo IAU/USP, v.15, n 1. pp 06-22.

TARDIN, Raquel. (2010). Ordenação Sistêmica da Paisagem. ENANPARQ - Arquitetura, Cidade, Paisagem e Território: percursos e prospectivas. Rio de Janeiro.

TRINDADE JÚNIOR, S. C. (2010). Cidades na floresta: "os grandes objetos"como expressão do meio técnico-científico informacional no espaço Amazônico. Revista IEB, n 50, set/mar. pp. 13-138

VESCINA, L. M. (2010). Projeto urbano, paisagem e representação Alternativas para o espaço metropolitano. PROURB - Programa de Pós-Graduação em Urbanismo - Faculdade de Arquitetura e Urbanismo Universidade Federal do Rio de Janeiro.

VILLAÇA, Flávio. Espaço Intra-Urbano no Brasil. Studio Nobel: FAPESP, São Paulo, 2001. 